\title{
The helminth community of the Mediterranean mouse, Mus spretus, in a post- fire regenerated Mediterranean ecosystem
}

\author{
S. SAINZ-ELIPE, M. T. GALÁN-PUCHADES, M. V. FUENTES*
}

Departament de Parasitologia, Facultat de Farmàcia, Universitat de València, Av. Vicent Andrés Estellés s/n, 46100 Burjassot-València, Spain, E-mail: mario.v.fuentes@uv.es

\begin{abstract}
Summary
The helminth community of the Mediterranean mouse, Mus spretus, was analysed in a post-fire regenerated Mediterranean ecosystem. The study was carried out in the Spanish Natural Park of the Serra Calderona and comprised a 13 year period, from the $2^{\text {nd }}$ to the $14^{\text {th }}$ year after a wildfire. A total of 121 host individuals was analysed, 66 mice from the burned area and 55 from the non-burned area used as control. The results show a helminth community consisting of 10 helminth species, characterised by low diversity, with Syphacia obvelata as the only dominant helminth species. The helminth infracommunity, determined by its origin of capture, burned or non-burned areas, shows some significant differences. It is concluded that the helminth community of the Mediterranean mouse could be considered as a potential biological tag of the post-fire regeneration in Mediterranean ecosystems and therefore might explain some of the changes occurring and their repercussions in perturbed areas.
\end{abstract}

Key words: helminth community; Mus spretus; post-fire; Mediterranean ecosystem; Serra Calderona; Spain

\section{Introduction}

The Mediterranean mouse, Mus spretus, closely related to the house mouse, M. musculus, is an endemic murine species distributed in the western Mediterranean region, from a part of France to Spain, Portugal and some north African countries. This local distribution might be the reason for the small number of studies carried out concerning the analysis of the helminthfauna of this small rodent. Moreover, only few of these studies reported quantitative data on $M$. spretus parasites, Behnke et al. (1993) from the Setubal Peninsula (Portugal), Fuentes et al. (2000) from Serra Calderona (Spain), Torres et al. (2003) from Doñana National
Park (Spain) and Sainz-Elipe et al. (2004) from the biogeographical Mediterranean region of Navarra (Spain). Consequently, and with the aim to shed more light on the Mediterranean mouse helminthfauna, and as a part of a multidisciplinary project focused on the role played by small mammal helminths in the post-fire ecosystem regeneration processes, the helminth community of $M$. spretus was analysed in the Spanish Natural Park of the Serra Calderona a Mediterranean ecosystem in regeneration 14 years after a wildfire, following the methodology proposed by GalánPuchades et al. (1999).

\section{Material and Methods}

The study area is a Spanish Mediterranean ecosystem located in the Serra Calderona Natural Park $\left(39^{\circ} 35^{\prime}-39^{\circ} 51^{\prime} \mathrm{N}\right.$, $\left.0^{\circ} 15^{\prime}-0^{\circ} 43^{\prime} \mathrm{W}\right)$, a mountain-range situated in Comunitat Valenciana, with a surface of 52,000 ha, which suffered a large wildfire at the end of the summer of 1992 affecting a total of 9,500 ha including forests and cultivated land which had been left untended.

A multidisciplinary project concerning the post-fire recolonization dynamics of small mammals and the study of their helminth parasites as biological tags in the process of post-fire regeneration was initiated in February 1994, the winter of the $2^{\text {nd }}$ year after fire. The present article includes the study of 121 individual Mediterranean mice, M. spretus, captured prior to September 2006, the summer of the $14^{\text {th }}$ year after fire. Sixty-six individual hosts originated from the burned area and 55 from the control area.

The host material was obtained in trapping sessions using the capture-recapture method, seasonal/annual collection of data according to the methodology described by GalánPuchades et al. (1999) and Fuentes et al. (2000).

For the extraction of helminths and after collecting the data

\footnotetext{
* Corresponding author
} 
on each individual host, routine procedures were used in the dissection and study of all organs. The helminths detected were studied applying standard helminthological techniques (Fuentes et al., 2000). All helminths were specifically identified based on their morphology and morphometry, and employing the most relevant literature on each of the species involved. A number of specimens could not be specifically classified due to the limited development within the host or morphologically non-differentiable adults at species level (as in trematode species), or the detection of larval stages or immature nematode adults, respectively.

The study was carried out comparing the burned area with the control area globally. The analysis of the helminth community composition and structures for both burned and non-burned areas was carried out considering each particular biological cycle and calculating the prevalence, mean abundance, median intensity and range according to Bush et al., 1997. The study of the helminth biological cycles was carried out differentiating between free-environmental stage (FES) borne and invertebrate-borne (no-FES) helminthiasis and not the more commonly used classification between heteroxenous and monoxenous helminths (Fuentes et al., 2006).

The analysis of the helminth community components was carried out calculating the abundance index (Bush, 1973; Pence \& Eason, 1980), excluding those parasite species for which the Mediterranean mouse acts as an intermediate host, as well as the frequency distribution of helminths. This distribution was calculated by means of the Lefkovitch index $(\mathrm{L})$, by which $\mathrm{L}=(1 / 45) \operatorname{tang}^{-1}$ (variance/ mean)-1 ranges from -1 (positive binomial or uniform distribution), 0 (Poisson or random distribution) and +1 (negative binomial or aggregated distribution).

The diversity/uniformity analysis of the helminth community was completed by using the Shannon index (Pielou, 1975; Magurran, 1988), Simpson index (D) (Simpson, 1949) expressed as 1-D (Magurran, 1988), Berger-Parker index (Berger \& Parker, 1970; May, 1975; Magurran, 1988) and Shannon evenness index (Pielou, 1969; Magurran, 1988).

The helminth infracommunity structure study was carried out analysing the number of helminths, number of helminth species, the Brillouin index (Pielou, 1975; Magur- ran, 1988), Brillouin index for infected hosts only and percentage of infected hosts.

Where possible, the standard non-parametric chi-squared $\left(\chi^{2}\right)$ test was applied (Sokal \& Rohlf, 1981). The study was completed with the analysis of the role played by extrinsic (year and season of capture) and intrinsic (host age and sex) factors in determining species richness and helminth diversity of the helminth community of $M$. spretus in both capture sites, and in determining the prevalence and the mean abundance of Syphacia obvelata, the only dominant helminth species. Differences in sub-population prevalences were analysed using the $\chi^{2}$ test, and differences in subpopulation worm burdens were analysed using a multifactorial general linear model (GLIM). As the number of $S$. obvelata was highly aggregated, the helminth abundance of this species was normalized by the $\ln (\mathrm{x}+1)$ transformation for this GLIM analysis. Statistical significance was established at $\mathrm{P}<0.05$.

StatView 5.0 - SAS Institute Inc. - and SPSS 13.0 - SPSS Inc. - for Windows were the software packages used for statistical analyses.

\section{Results}

\section{Serra Calderona}

Sixty-six of a total of $121(54.6 \%)$ individual hosts analysed were parasitized with 10 species (Table 1). Fifty-nine $(48.8 \%)$ of the individuals analysed were infected with FES helminths, and $17(14.1 \%)$ were infected with noFES helminths. This difference was statistically significant $\left(\chi^{2}=32.245 ; \mathrm{P}<0.0001\right)$.

The values of the diversity/uniformity index of the helminth community were 0.26 for the Shannon index, 0.09 for the Simpson index, 0.05 for the Berger-Parker index and 0.11 for the Shannon evenness index.

\section{Burned area}

Forty-one of a total of 66 individual hosts analysed (62.1 $\%)$ were parasitized with 9 species: 1 trematode, 2 cestodes and 6 nematodes (Table 1). The most prevalent as well as the most abundant helminth was $S$. obvelata. Thirty-five $(53.0 \%)$ of the individuals analysed were infected with FES helminths, and $12(18.2 \%)$ were infected with noFES helminths. This difference was statistically significant

Table 1. Selected characteristics of the helminth fauna of all Mediterranean mice in burned (B) and control (C) areas

\begin{tabular}{|c|c|c|c|c|c|c|c|c|}
\hline \multirow[t]{2}{*}{ Helminth species } & \multirow[t]{2}{*}{ Site } & \multirow[t]{2}{*}{ LC } & \multicolumn{2}{|c|}{ Prevalence $(95 \% \mathrm{CI})$} & \multicolumn{2}{|c|}{ Mean abundance (SE) } & \multicolumn{2}{|c|}{ Median intensity (range) } \\
\hline & & & $\mathrm{B}$ & $\mathrm{C}$ & $\mathrm{B}$ & $\mathrm{C}$ & $\mathrm{B}$ & $\mathrm{C}$ \\
\hline Brachylaima spp. & I & NF & $3(0-11)$ & $4(1-13)$ & $0.1(0.07)$ & $0.1(0.08)$ & $4(3-4)$ & $3(2-4)$ \\
\hline Zonorchis sp. & GB & NF & - & $2(0-10)$ & - & $0.2(0.2)$ & - & $9(9)$ \\
\hline Mesocestoides sp. larvae & $\mathrm{BC}$ & $\mathrm{NF}$ & $5(1-13)$ & $2(0-10)$ & $0.5(0.3)$ & $0.3(0.3)$ & $10(3-30)$ & $18(18)$ \\
\hline Catenotaenia pusilla & I & $\mathrm{NF}$ & $2(0-9)$ & - & $0.02(0.02)$ & - & $1(1)$ & - \\
\hline Eucoleus bacillatus & $\mathrm{S}$ & $\mathrm{F}$ & $6(2-15)$ & $15(7-27)$ & $0.2(0.1)$ & $0.7(0.3)$ & $3(1-4)$ & $3(1-11)$ \\
\hline Heligmosomoides polygyrus & I & F & $6(2-15)$ & $4(1-13)$ & $0.1(0.04)$ & $0.1(0.06)$ & $1(1-2)$ & $2(1-3)$ \\
\hline Syphacia obvelata & I & F & $44(32-57)$ & $29(18-43)$ & $27.2(10.2)$ & $22.2(7.9)$ & $6(1-429)$ & $30(1-330)$ \\
\hline Aspiculuris tetraptera & I & $\mathrm{F}$ & $2(0-9)$ & - & $0.02(0.02)$ & - & $1(1)$ & - \\
\hline Mastophorus muris & $\mathrm{S}$ & NF & $9(4-19)$ & $4(1-13)$ & $0.1(0.06)$ & $0.04(0.03)$ & $1(1-3)$ & $1(1)$ \\
\hline Nematoda gen. sp. larvae & $\mathrm{I} / \mathrm{BC}$ & $\mathrm{F}$ & $3(0-11)$ & $2(0-10)$ & $0.1(0.05)$ & $0.04(0.04)$ & $3(2-3)$ & $2(2)$ \\
\hline
\end{tabular}

$\mathrm{CI}$ - confidence interval; SE - standard error; LC - life cycle; I - intestine; GB - gall bladder; BC - body cavity; S - stomach 
Table 2. Abundance index (AI) and Lefkovitch index (L) of all Mediterranean mice in burned (B) and control (C) areas

\begin{tabular}{|c|c|c|c|c|}
\hline \multirow[t]{2}{*}{ Helminth species } & \multicolumn{2}{|c|}{ AI } & \multicolumn{2}{|c|}{$\mathrm{L}$} \\
\hline & B & $\mathrm{C}$ & B & $\mathrm{C}$ \\
\hline Eucoleus bacillatus & 0.17 & 0.65 & 0.62 & 0.83 \\
\hline Heligmosomoides polygyrus & 0.08 & 0.07 & 0.19 & 0.51 \\
\hline Syphacia obvelata & 27.15 & 22.22 & 0.99 & 0.99 \\
\hline Mastophorus muris & 0.12 & 0.04 & 0.31 & -0.01 \\
\hline
\end{tabular}

Table 3. Diversity characteristics of the helminth infracommunities of Mus spretus (M.s.) in Serra Calderona determined by areas of origin

\begin{tabular}{lccc}
\hline Characteristics & & $\mathrm{B}$ & $\mathrm{C}$ \\
\hline No. of helminths & $\mathrm{X}$ & 28.2 & 23.6 \\
& $\mathrm{SE}$ & 10.2 & 8.0 \\
No. of helminth species & & 9 & 8 \\
& $\mathrm{X}$ & 0.8 & 0.6 \\
& $\mathrm{SE}$ & 0.1 & 0.1 \\
Brillouin index & $\mathrm{X}$ & 0.06 & 0.04 \\
& $\mathrm{SE}$ & 0.02 & 0.02 \\
B.I. infected M.s. only & $\mathrm{X}$ & 0.09 & 0.09 \\
& $\mathrm{SE}$ & 0.03 & 0.04 \\
Percentage of M.s. infected & & 62.1 & 45.5 \\
\hline
\end{tabular}

B - burned area; C - control area

$\left(\chi^{2}=15.992 ; \mathrm{P}<0.0001\right)$.

The analysis of the abundance index values (Table 2) makes it possible to establish the following helminth community structure: $S$. obvelata as the dominant species; $E u$ coleus bacillatus, Mastophorus muris and Brachylaima spp. as co-dominant species; Heligmosomoides polygyrus, Catenotaenia pusilla and Aspiculuris tetraptera as successful immigrant species.

The analysis of frequency distributions for the various helminth populations (Table 2) shows that the four most prevalent species have a negative distribution. The very high aggregation of $S$. obvelata and the low aggregation of $H$. polygyrus stand out.

Table 3 shows the diversity of the infracommunities determined by the Brillouin value index taking into account the total of each infracommunity as well as that of the infested hosts only.

\section{Control area}

Twenty-five of a total of 55 individual hosts analysed (45.5 $\%)$ were parasitized with 8 species: 2 trematodes, 1 cestode and 5 nematodes (Table 1). In this non-burned area, the most prevalent and abundant species was $S$. obvelata, the same as in the burned area. Twenty-four (43.6\%) of the individuals analysed were infected with FES helminths, and $5(9.1 \%)$ were infected with no-FES helminths. This difference was statistically significant $\left(\chi^{2}=16.908 ; \mathrm{P}<\right.$ $0.0001)$.

The analysis of the abundance index values (Table 2) makes it possible to establish a very similar helminth community structure as found in the burned area, taking into account the three different helminth species not detected in the burned or control area, while merely M. muris, seemingly a successful immigrant species, and Zonorchis sp., an unsuccessful immigrant species, stand out.

The analysis of frequency distributions for the various helminth populations (Table 2) shows that $H$. polygyrus is more aggregated, and M. muris has a random distribution the only remarkable difference with the burned area.

The study of the diversity of the infracommunities determined by the Brillouin value index (Table 3) reveals a similar diversity in the burned as well as in the control areas.

The role of extrinsic and intrinsic factors in the helminth community

No statistically significant differences were found concerning species richness and helminth diversity between the

Table 4. Helminth abundance of Syphacia obvelata in Mus spretus from Serra Calderona burned and control areas by season and year of capture, host age and host sex, through a multifactorial GLIM, expressed by F - statistic values with associated probabilities (P), df - degree of freedom. Only statistically significant values are reported

\begin{tabular}{|c|c|c|c|c|c|c|}
\hline \multirow[t]{2}{*}{ Source of variation } & \multicolumn{3}{|c|}{ Burned area } & \multicolumn{3}{|c|}{ Control area } \\
\hline & $\mathrm{df}$ & $F$ & $P$ & $\mathrm{df}$ & $F$ & $\mathrm{P}$ \\
\hline Season of capture & 3 & 9.340 & $<0.0001$ & & & \\
\hline Year of capture & 8 & 8.235 & $<0.0001$ & 7 & 20.433 & $<0.0001$ \\
\hline Host age & 2 & 5.897 & 0.008 & & & \\
\hline Host sex & 1 & 6.325 & 0.019 & & & \\
\hline Season of capture/year of capture & 1 & 49.162 & $<0.001$ & & & \\
\hline Season of capture/host age & & & & 3 & 5.891 & 0.007 \\
\hline Season of capture/host sex & 2 & 7.457 & 0.003 & & & \\
\hline Year of capture/host age & & & & 5 & 19.179 & $<0.0001$ \\
\hline Year of capture/host sex & & & & 5 & 4.316 & 0.011 \\
\hline Host age/host sex & & & & 2 & 13.138 & $<0.0001$ \\
\hline
\end{tabular}


infracommunities determined by site, year and season of capture, host age and sex. However, the study of the role played by these factors on prevalence and helminth abundance of $S$. obvelata showed that its prevalence is determined by year of capture $\left(\chi^{2}=26.836 ; \mathrm{P}=0.0008\right)$ in the burned area only, and its worm burden is determined, in both sites, by various extrinsic and intrinsic factors as well as by their interactions (Table 4).

\section{Discussion}

The dicrocelid Zonorchis sp., parasitizing the gall bladder of a Mediterranean mouse, were detected for the first time in the helminth community of this host. This trematode, as unsuccessful immigrant species, has to be considered a very rare helminth species probably requiring a small mammal insectivore or a bird as its natural definitive host. The absence of this trematode in other small mammal helminth communities analysed in this enclave (Fuentes et al., $2000,2005)$ reinforces the postulation that this helminth generally parasitizes other definitive hosts, but not small mammals. Four of the 7 helminth species previously reported by Fuentes et al. (2000) to parasitize the Mediterranean mouse in the Serra Calderona Natural Park act, according with the helminth community structure and components of $M$. spretus, as the reservoir host for helminthiases specific of other murid hosts required (i.e. E. bacillatus and $H$. polygyrus for Apodemus sylvaticus, and $A$. tetraptera and M. muris for Rattus rattus).

The global helminth prevalence reported here is higher than that reported in other Spanish enclaves studied, i.e. the National Park of Doñana, 51.7 \% (Torres et al., 2003) and the Mediterranean region of Navarra, $33.7 \%$ (SainzElipe et al., 2004), but lower than that found by Behnke et al., 1993 in the Portuguese peninsula of Setubal, $75.8 \%$. However, the absence of hymenolepidid and larvae of taenid species stands out in contrast with some of the other above-mentioned Iberian enclaves. The diversity/uniformmity index analysis shows, in general, a helminth community diversity similar to that reported in Setubal and Doñana, but higher than that in Navarra. Nevertheless, the very low value of the Berger-Parker index correlates with the clear dominance of $S$. obvelata. On the other hand, the higher prevalence of FES helminths might be related with the diet of this murid, which does not include a great quantity of invertebrates, and with the behaviour of the Mediterranean mouse (Behnke et al., 1993), which makes a higher transmission of $S$. obvelata possible.

If we compare the burned and control area from a qualitative point of view, the only difference between these infracommunities is the absence of 2 helminth species in the control area, C. pusilla and A. tetraptera, and the absence of Zonorchis sp. in the burned area. These absences are probably of little significance as these 3 species parasitized only 1 individual host each.

The most prevalent as well as the most abundant helminth species in both infracommunities remains $S$. obvelata, and, although the values are greater in the burned-area infra- communities, the differences are statistically insignificant. This oxyurid presents a clear negative binomial distribution in both study areas. This highly aggregated distribution concentrates the effect of density-dependent limitation on parasitism leading to a potential stabilizing influence (Shaw \& Dobson, 1995), i.e. the only dominant species of the helminth community has a low destabilizing capacity on the Mediterranean mouse population.

Prevalences of $S$. obvelata were affected only by the year of capture in the burned area. Moreover, the year of capture was the only factor which directly affected the $S$. $o b$ velata burden in the control area, while in the burned area the mean abundance of this oxyurid was directly affected by the 4 factors analysed - extrinsic and intrinsic. In both areas, the 6 possible pair interactions seem to play a role in the determination of the $S$. obvelata burden. However, the effect of the season and the year of capture, as well as their combination in the burned area are noteworthy since they might be related to the effect of the fire in the burned area. The changes occurring between the seasons of each year of capture should affect the host population dynamics more strongly, and consequently the host behaviour in the burned area. Thus, the other interactions might be explained by the usual, but irregular, fluctuations of the Mediterranean mouse community in its natural habitat.

The differences found between the helminth community of the Mediterranean mouse in the 2 areas studied during the 13 year post-fire regeneration process in the Serra Calderona Natural Park, allow us to postulate the analysis of the helminth community of $M$. spretus as a potential biological tag of the post-fire regeneration in Mediterranean ecosystems, which could explain some of the changes and their repercussions in perturbed areas. The real significance of this postulation will be confirmed by future analyses including more helminthological material as well as the analysis of the host dynamics in the burned and control areas.

\section{Acknowledgements}

This study has been supported by Projects: GV05/001, Conselleria d'Empresa, Universitat i Ciència, Generalitat Valenciana, Spain; PB87-0135 and PB92-0517-C02-01, Ministerio de Educación y Ciencia and BOS 2000-0570C02-02, Ministerio de Ciencia y Tecnología, Madrid, Spain; CPE/073, Institució Valenciana d'Estudis i Investigació, València, Spain; UV-AE 20060233 and UV97-2216 of the Universitat de València, Spain. S. Sainz-Elipe received a personal postgraduate scholarship from the Fundació La Caixa, Barcelona, Spain. We would also like to thank the Conselleria de Medi Ambient de la Generalitat Valenciana, València (Spain) for the permissions to carry out field studies.

\section{References}

Behnke, J. M., Barnard, C., Hurst, J. L., Mcgregor, P. K., Gilbert, F., LEWIS, J. W. (1993): The prevalence and intensity of infection with helminth parasites in Mus 
spretus from the Setubal Peninsula of Portugal. $J$. Helminthol., 67: $115-122$

Berger, W. H., PARKER, F. L. (1970): Diversity of planktonic Foraminifera in deep sea sediments. Science, 168: $1345-1347$

Bush, A. O. (1973): An ecological analysis of the helminth parasites of the white ibis in Florida. M. S. Thesis, Univ. Florida, Gainsville-Florida

Bush, A. O., Lafferty, K. D., Lotz, J. M., Shostal, A. W. (1997): Parasitology meets ecology on its own terms: Margolis et al. revisited. J. Parasitol., 83: 575 - 583

Fuentes, M. V., Cerezuela, A. M., Galan-Puchades, M. T. (2000): A helminthological survey of small mammals (insectivores and rodents) in the Serra Calderona mountains (Valencian Community, Spain). Res. Rev. Parasitol., 60: $25-35$

Fuentes, M. V., Sainz, S., Galan-Puchades, M. T. (2005): The helminth community of the common shrew in a post-fire regenerated Mediterranean ecosystem. Helminthologia, 42: $31-34$

Fuentes, M. V., Sainz-Elipe, S., Galan-Puchades, M. T. (2006): Comparative analysis of the helminth community of the common shrew, Crocidura russula, of three western Mediterranean enclaves and the inland of the Iberian Peninsula. Res. Rev. Parasitol., 65, in press

Galan-Puchades, M. T., Fuentes, M. V., Cerezuela, A. M., Fons, R., MAS-COMA, S. (1999): A proposed methodology for the use of helminth parasites as biological tags in the study of post-fire ecosystem regeneration processes. Vie Milieu, 49: 45 - 50

MagurRAN, A. E. (1988): Ecological diversity and its measurement. Croom Helm, Ltd., London

MAY, R. M. (1975): Patterns of species abundance and diversity. In CODY, M. L. and DiAMOND, J. M. (Eds.): Ecology and evolution of communities, Harvard University Press, Cambridge

Pence, D. B., EAson, S. (1980): Comparison of the helminth faunas of two sympatric top carnivores from the Rolling Plains of Texas. J. Parasitol., 66: $115-120$

PIELOU, E. C. (1969): An introduction to mathematical ecology. John Wiley \& Sons, New York

PIELOU, E. C. (1975): Ecological diversity. Wiley Interscience, New York

SAinz-EliPe, S., Galicia, D., ImaZ, A., Galan-PuChaDES, M. T., FuENTES, M. V. (2004): The helminth community of Mus spretus (Rodentia: Muridae) in the biogeographical Mediterranean region of Navarra (Spain). Res. Rev. Parasitol., 64: 55 - 58

SHAw, D. J., Dobson, A. P. (1995): Patterns of macroparasite abundance and aggregation in wildlife populations: a quantitative review. Parasitology, 111: 111 - 133

SIMPSON, E. H. (1949): Measurement of diversity. Nature, 163: 688

SOKAL, R. R., RoHLF, F. J. (1981): Biometry. The principles and practice of statistics in biological research. $2^{\text {nd }}$ Ed. W.H. FreEMAN and Co, New York

Torres, J., Trelis, M., Espert, A., Ribas, A., Toledo, R., Casanova, J. C., Roman, J., Arrizabalaga, A., EsteBAN, J. G., FELIU, C. (2003): Helminth fauna of small mammals (insectivores and rodents) in Doñana (southeastern Iberian Peninsula). Res. Rev. Parasitol., 63: 23 29

ACCEPTED JUNE 15, 2007 